\title{
Health-seeking behaviour and community perceptions of childhood undernutrition and a community management of acute malnutrition (CMAM) programme in rural Bihar, India: a qualitative study
}

\author{
Doris Burtscher ${ }^{1}$ and Sakib Burza ${ }^{2, *}$ \\ ${ }^{1}$ Médecins Sans Frontières (MSF), Vienna, Austria: ${ }^{2}$ Médecins Sans Frontières (MSF), C203 Defence Colony, \\ New Delhi 110024, India
}

Submitted 10 March 2014: Final revision received 16 December 2014: Accepted 16 January 2015: First published online 10 March 2015

\begin{abstract}
Objective: Since 2009, Médecins Sans Frontières has implemented a community management of acute malnutrition (CMAM) programme in rural Biraul block, Bihar State, India that has admitted over 10000 severely malnourished children but has struggled with poor coverage and default rates. With the aim of improving programme outcomes we undertook a qualitative study to understand community perceptions of childhood undernutrition, the CMAM programme and how these affected health-seeking behaviour.

Design: Semi-structured and narrative interviews were undertaken with families of severely malnourished children, non-undernourished children and traditional and allopathic health-care workers. Analysis of transcripts was by qualitative content analysis.

Setting: Biraul, Bihar State, India, 2010.

Subjects: One hundred and fifty people were interviewed in individual or group discussions during fifty-eight interviews.

Results: Undernutrition was not viewed as a disease; instead, local disease concepts were identified that described the clinical spectrum of undernutrition. These concepts informed perception, so caregivers were unlikely to consult health workers if children were 'only skinny'. Hindu and Muslim priests and other traditional health practitioners were more regularly consulted and perceived as easier to access than allopathic health facilities. Senior family members and village elders had significant influence on the health-seeking behaviour of parents of severely malnourished children.

Conclusions: The results reaffirm how health education and CMAM programmes should encompass local disease concepts, beliefs and motivations to improve awareness that undernutrition is a disease and one that can be treated. CMAM is well accepted by the community; however, programmes must do better to engage communities, including traditional healers, to enable development of a holistic approach within existing social structures.
\end{abstract}

Keywords Malnutrition India

Traditional disease concepts Health-seeking behaviour Community management of malnutrition
In 2006, the National Family Health Survey-3 estimated that in India eight million children younger than 5 years suffer from severe acute malnutrition $(S A M)^{(1)}$. In the Indian context, where malnutrition levels are considered to be much higher than in other countries ${ }^{(2)}$, it is estimated that $67 \%$ of deaths occurring in children under 5 years of age are attributable to the potentiating effects of undernutrition $^{(3)}$. Childhood undernutrition is known to be multifactorial, with maternal undernutrition and resultant low birth weight ${ }^{(4,5)}$, poor diet, economic inequalities ${ }^{(6)}$, lack of health services and diseases such as diarrhoea ${ }^{(6)}$ all being major contributors to a vicious cycle that has proved very challenging to break.

As in many resource-poor settings, the provision of health care in rural India is often challenged by a shortage of health centres and health workers. This issue is compounded by poor transport networks making it difficult to travel to the few centres that exist ${ }^{(7)}$, lack of faith in the public health sector and other practical factors such as whether patients can afford to pay for treatment. Darbhanga is one of the most disadvantaged districts in Bihar, which itself is one of the India's poorest states. 
Its inhabitants have an annual per capita income of \$US 443 compared with India's average of \$US 1095; $42.6 \%$ of the population lives below the poverty line compared with the national average of $26 \cdot 1 \%^{(8,9)}$. Male literacy is $36 \%$ and female literacy is $12 \%{ }^{(7)}$.

After a nutritional survey demonstrated a $4.8 \%$ prevalence of SAM in Darbhanga district in $2008^{(10)}$, under a Memorandum of Understanding with the district authorities, Médecins Sans Frontières (MSF), a medical humanitarian non-governmental organisation, established a communitybased management of severe malnutrition programme in Biraul block. Biraul block has a population of $300000^{(11)}$ and is one of eighteen administrative areas within Darbhanga district. Although widely practised outside India, community management of acute malnutrition (CMAM) is a relatively new concept in India, where management of SAM remains mostly based within in-patient facilities ${ }^{(12)}$. In this CMAM programme, children aged between 6 months and 5 years with SAM (not moderate acute malnutrition) are identified through the measurement of their upper arm circumference using a simple plastic tape ${ }^{(13)}$. Children with a mid-upper arm circumference of $<115 \mathrm{~mm}$, and/or those with bilateral swelling (oedema) attributable to undernutrition, are considered to be suffering from SAM. These measurements are carried out mostly in the community and primary health-care centres by community health workers, government nurses and CMAM programme staff.

Once children are identified as having SAM, mothers are counselled about the condition and what the treatment involves. After initial standardised systemic treatment for infection and vitamin deficiency, the main component of treatment is an Indian-produced, pre-packaged, WHOstandard F100-equivalent oil-based paste, which is given in predetermined quantities based on the weight of the child. On average, treatment entails once weekly visits to the community-based heath-care facility for review and to receive the following week's treatment; the average length of treatment is 7 weeks. Considering the relatively long duration of treatment for SAM, the objective of CMAM is to provide ambulatory nutritional care close to the caregiver's home so that there is minimal disruption of the caregiver's day-to-day activities. This in turn minimises the societal impact of treatment, reduces costs to health-care providers and increases compliance with, and acceptability of, treatment ${ }^{(14)}$.

The CMAM programme in Biraul block involves five therapeutic feeding centres treating ambulatory 'uncomplicated' SAM children and one in-patient stabilisation centre treating the more unwell 'complicated' SAM children who require in-patient care, where they are kept for the minimum amount of time necessary until they can be safely discharged into the community component of care to complete treatment.

In 4 years, the programme has admitted over 10000 children, with just over half the children travelling for treatment from outside the block. However, repeated semi-quantitative evaluation of access and care (SQUEAC) surveys suggested that there were many more children with SAM within the block who were not being treated in the programme ${ }^{(15)}$. Additionally, the programme struggled with default rates as high as $38 \%$, particularly in those caregivers who were commuting from outside the block $^{(16)}$. Data from other facility-based nutritional programmes across India suggest that defaulting is an issue in other states ${ }^{(17)}$, reaching $47 \cdot 2 \%$ in in-patient only nutritional rehabilitation centres in Uttar Pradesh ${ }^{(18)}$.

Evidence that different understandings of physiological states exist and vary between cultures has been well described by medical anthropologists, as have the many other social and cultural factors in play that influence health-seeking behaviour. However, in-depth understanding of community perception and social aspects of undernutrition and CMAM was absent in this context, which placed a substantial barrier to effective and sustainable programme implementation. In order to help identify the underlying causes of poor coverage and default from the CMAM programme, we therefore undertook a qualitative study in Biraul block to understand the community perceptions of undernutrition and the CMAM programme, and how these affected health-seeking behaviour. The objective was to develop evidence that would be used to adapt the CMAM programme in order to improve outcomes and develop a more appropriate health promotion strategy for the community so as to provide more effective care for the target population.

\section{Methods}

Over a 5-week period, qualitative semi-structured interviews (Table 1), using a topic guide (see online supplementary material, Supplemental Figs 1-3), and narrative interviews were conducted with families (mothers, fathers and mothers-in-law) of children treated for severe malnutrition (approximately two-thirds of family interviewees), families containing children without severe malnutrition (one-third of family interviewees) and healthcare workers (traditional healers, Hindu and Muslim priests, traditional health practitioners, midwives, hospital nurses, health educators and doctors). Approximately 150 people participated in the discussions, which comprised: (i) forty-four one-to-one in-depth key informant interviews in the participants' first language (Maithili); (ii) five focus group discussions with five to ten people participating; and (iii) nine natural group interviews, with an average of six people participating. Many discussions tended to become natural group interviews, which has been recognised in other resource-poor settings ${ }^{(19)}$; when conducting interviews in people's homes or public places, it is often difficult to restrict questions to a single individual since relatives or friends frequently join in the conversation. Most participants were female: in the individual interviews, about two-thirds of participants were female; all 
Table 1 Respondent and interview characteristics, Biraul, Bihar State, India, 2010

\begin{tabular}{lrr}
\hline & $n$ & $\%$ \\
\hline Respondent characteristics ( $\left.n_{\text {interviewees }} 150\right)$ & & \\
Age & & \\
$<25$ years & 38 & 25 \\
$25-<45$ years & 84 & 56 \\
$>45$ years & 28 & 19 \\
Gender & & \\
Male & 42 & 28 \\
Female & 108 & 72 \\
Caste & & \\
Scheduled caste & 73 & 49 \\
Other backward classes & 57 & 38 \\
General category & 15 & 10 \\
Missing & 5 & 3 \\
Religion & 120 & 80 \\
Hindu & 28 & 19 \\
Muslim & 2 & 1 \\
Other & & \\
Target groups & 87 & 58 \\
Caregivers & 37 & 25 \\
Traditional birth attendants & 13 & 9 \\
Allopathic health care workers & 8 & 5 \\
Priest/healer & 5 & 3 \\
Accredited social health activist & & \\
Interview type $\left(n_{\text {interviews }}\right.$ 58) & 44 & 76 \\
Individual interview & 9 & 15 \\
Group discussions (average six participants) & 5 & 9 \\
Focus group discussions (five to ten participants) & & \\
& &
\end{tabular}

focus group discussions were women only; and in the natural group interviews, one was men only, five women only and three were mixed.

Participants were selected by purposive sampling ${ }^{(20)}$ of individuals likely to provide useful accounts in relation to the study objectives (parents who had malnourished children or health-care workers). Informants with children aged 6 months to 5 years old with SAM were selected from a geographical sampling frame of children admitted to the programme, while families of children without SAM were identified through the snowball technique, with interviewees asked to identify others (such as families without malnourished children) who might agree to be interviewed. Participant selection was supported by CMAM mobile teams and community health workers. The number of participants interviewed was determined through achieving thematic saturation. Most interviews (70\%) were with caregivers (mothers, grandmothers or mothers-inlaw), the remaining other discussions (30\%) were with health staff (allopathic 16\% and non-allopathic 14\%). Informants were drawn from differing religious and caste* backgrounds. Most interviewees were from 'scheduled

* Caste is a form of social stratification used in India and the categories used in the present study were: scheduled caste, other backward class and general category. Other backward class is a collective term used by the Government of India for castes that are educationally and socially disadvantaged. Scheduled caste is a term used for two groups of historically disadvantaged people recognised in the Constitution of India. These three groups combined account for approximately $60 \%$ of India's population. General category comprises those who do not fit within the other categories and are not considered to be disadvantaged. caste' (50\%) and 'other backward class' (40\%); while $10 \%$ of interviewees identified as being of 'general category' castes. From the religious affiliation perspective, $80 \%$ of interviewees were Hindu and $20 \%$ were Muslim, reflecting the background demographic in the district.

Interviews were not tape-recorded, but detailed notes were taken during interviews and a field diary was kept. Accurate understanding and interpretation of the nuances of the interviews required a translator competent in both Maithili and English. As such, a translator known to the community and familiar with the area, demographics and functioning of the CMAM programme was selected who was able to create a relaxed atmosphere with all the interviewees. Respondents appeared comfortable with both interviewer and translator; the great majority were already aware of the CMAM programme and that it was being supported by an international non-governmental organisation.

The majority of interviews were held in the homes of the participants, either inside a room or at a place chosen by the participants themselves. A limited number were held in health facilities, either in a separate room or outside in the backyard. Linguistic barriers meant that wordfor-word translations were occasionally not possible. Ambiguities in the interviews were subsequently crosschecked with local staff working in the CMAM programme who were also fluent in Maithili. Respondents appeared keen to discuss their experiences in relation to undernutrition and the CMAM programme, and were aware that the interviewer was from the health-care organisation providing the CMAM services.

\section{Data analysis}

Interview data were fully transcribed, coded and analysed by the principal investigator. Content analysis constituted the basis of the analysis; constant comparison between participants' accounts was used to explore the similarity and differences between individuals and between the purposively selected groups. The transcripts were screened for relevant information, which was organised, coded, categorised and interpreted. The coding process categorised data thematically with codes generated on the basis of what emerged from the collected data and using theoretical concepts such as 'perception of illness', 'treatment taking behaviour', 'ethnophysiology', 'adherence', 'perception of recovery' and 'treatment pathways'.

A manual of coding was developed to identify the central concepts that emerged, enabling description of categories, themes and patterns related to the research question. The rigour and validity of collected data were assessed by triangulation both before and during analysis; prior to commencing interviews, a thorough literature review was performed to identify relevant literature, such as Indian case studies of pregnancy dietetics and perceptions of popular medicine ${ }^{(21,22)}$. Respondent validation was applied in discussing data with participants, while observations taken during field research were discussed with experienced local 
staff from the CMAM programme on a daily basis following conclusion of interview. Deviant cases were taken into consideration and discussed where relevant.

\section{Results}

The results are presented grouped into three major emergent themes, each with several sub-themes. Since undernutrition was attributed to local disease concepts, of which all respondents were aware, community perceptions of childhood undernutrition and health-seeking behaviour did not appear to differ between caregivers who had severely malnourished children and those who did not. The thematics appeared consistent and culturally based, with little variation across caste and religion.

\section{Community perception and concepts of undernutrition}

\section{Mamarcha}

'It is not a disease but we treat it as a seriousness.'

All respondents mentioned mamarcha, a local term for a sickness that matches moderate malnutrition. It was described as being extremely common in early childhood and mothers reported treating their children for it even if the child had no symptoms.

The symptoms of mamarcha were described as having big eyelids, weakness, wanting to lay down in cool places or eating salty food, having no appetite, watery diarrhoea and a swollen belly. Symptoms also included the child not being able to walk properly and preferring to crawl. According to the mothers, mamarcha was the result of a child eating 'delicious' salty or adult food too early, or as a result of there not being enough food in the family, or of the child not drinking its mother's milk.

When describing mamarcha, non-allopathic health practitioners spoke of a swollen liver, blisters on the tongue, lack of fluids in the body, shortage of blood, anaemia, thin arms and legs, weakness, severe irritability, lethargy and a swollen belly. Allopathic health workers said that mamarcha was caused by undernutrition, anaemia, a shortage of blood due to insufficient birth spacing, suckling while mothers were pregnant, worms in the digestive system, lack of food, lack of health care or a poor diet.

Almost all female respondents said that they primarily treated the child themselves and that mamarcha medicine could be found in any pharmacy in liquid form or at the local market as herbal medicine. Most mothers said that they went to the traditional health practitioner, primary health centre or hospital only if the child did not recover.

\section{Jallachatu}

The symptoms of what most Maithili people call jallachatu match those of severe malnutrition. Female caregivers noted that children with jallachatu were often born looking very thin, 'like a bird', and continued to get thinner after birth. Jallachatu was believed to occur if a vulture flew over a mother during her pregnancy:

'When the vulture crosses over the pregnant woman then the child will be delivered as very weak and slim, and no matter what you do it will keep on being slim and will not gain weight and it will not survive.'

All but one mother-in-law described jallachatu as being an attack by a witch that could only be treated by a Muslim or Hindu priest. Among other respondents, there were a variety of ideas about how jallachatu should be treated. Some respondents (fewer than half), who understood the Hindi word kuposan ( $k u$ means deficiency or lack and posahar means nutrition or nourishment) and were already familiar with the CMAM programme, said that kuposan and jallachatu were the same entity, and that both could be treated within the CMAM programme. Numerous others without exposure to the CMAM programme insisted jallachatu should only be treated by traditional health practitioners:

'[...] The only way to treat it is with cow dung. You put it into a bag, and we hang it at the back of the house for one month, and when it is dried we throw it into a river. As the cow dung swells in the water then the body of the child swells too. It is the same for girls. The cow dung is not mixed with anything.'

Traditional midwives reported that they treated the condition by heating mustard seeds in mustard oil in order to evoke an aroma to drive away the vulture, or by throwing dried cow dung into the river. The cow dung was seen as a proxy for the child's body; when it swells in the water, the child puts on weight. The majority of caregivers reported that they first consulted the Muslim or Hindu priest and if the child did not improve, mothers would consult an alternative traditional health practitioner or go to the CMAM feeding centres.

\section{Other concepts around feeding and nutrition}

Chamaki, or convulsions, was frequently mentioned in relation to undernutrition. Most mothers said that their children could have convulsions when they were thin and weak. Chamaki was thought to be caused by witches and could be treated by priests.

Hakarani was the term used to describe persistent crying. Some mothers believed it results from a lack of breast milk, but others said it was the result of an attack by a witch because the child 'is good looking, beautiful and handsome.' One Hindu priest described the use of ashes of cow dung or sacred ashes to treat the child by applying the ashes on the child's body and/or by giving some to the child to eat.

Nazar, also known as the 'evil eye', was mentioned by all respondents and described as being a look believed to 
be able to cause injury, or bad luck, to the person at whom it was aimed for reasons of envy or dislike. It was commonly perceived that it originated from individuals in the community (mostly widows) who could transmit a curse to the child, causing illness, wasting or even death. The primary victims were thought to be young children because they were often praised, precious and beautiful. One of the techniques used to protect the child mentioned by caregivers and priests was the application of soot around the eyes, which made the child appear 'ugly'. Over half of caregivers reported that they would not take children under 6 months of age to the field where they worked out of fear of exposing them to nazar; as such, they were left at home meaning that for the duration of the work day the child was not breast-fed, in turn predisposing them to becoming weak. Fewer efforts were made to protect female children against nazar compared with males; indeed, females appeared to be disadvantaged in a number of other ways, with lower level of importance during mealtime food distribution, and the threshold for seeking health care and treatment for SAM for female children appeared to be higher than that for male children.

\section{Health-seeking behaviour and community perception of the community management of acute malnutrition programme}

Since undernutrition was generally not considered to be a disease by mothers, they sought to understand it from the perspective of traditional medicine. Thus, most mothers did not consult traditional health practitioners or visit primary health-care centres if their child was 'only skinny'. If the mothers felt their child required medical treatment, their initial action was to provide medication themselves. If these were not effective, they would then consult a health practitioner. Several allopathic and non-allopathic health-care options were available to the caregivers, such as registered medical practitioners or traditional health practitioners.

The majority of mothers reported that they treated their children themselves on the advice of their in-laws or other elders before consulting a health-care provider, or through purchasing medicine recommended by local shopkeepers, whose opinion was generally accepted.

The majority of mothers reported managing their child themselves with mamarcha medicine, treating the jallachatu or by giving massages. This meant that the child's response determined if and when the mothers would then consult someone else. Caregivers noted that massaging their babies with oil was extremely important both in strengthening healthy babies and healing sick ones. All respondents reported that massages helped the child gain weight and that they used it particularly if a baby was thin; the skin was considered to possess the capacity to absorb healing substances, and by massaging the body the medicine mixed with oil seeped into the body from where it spread into the fat and then into the bones.

\section{Perception of allopathic and non-allopathic bealth-care systems}

Most respondents considered the CMAM programme to be functioning within the government allopathic health-care system. Allopathic health care included certified doctors and nurses and most respondents held them in high esteem, but reported that they were also expensive, and the quality of care not always consistent. Government primary health centres were most often located in bigger communities and often at a distance from villages. Most respondents stressed that even though drugs were supposed to be free of charge at primary health centres, they were generally of poor quality and sometimes unavailable. If drugs were unavailable, respondents said the doctor would then prescribe medication privately, for which they had to pay.

All respondents referred to any health practitioner who worked outside the primary health centre or hospital structures, and who was not a traditional health practitioner, as a 'private doctor', including the AYUSH doctors.* However, they did not recognise that the majority of these 'private doctors' were not allopathic physicians and generally felt that they understood better their perception of 'good' and 'bad' treatment.

\section{Traditional bealth practitioners}

Respondents described a wide spectrum of traditional birth attendants (dais), priests, witch doctors, tent doctors, local drug mixers (vaidhs), healers and Godmen as traditional health practitioners. They lived within the community and were usually the first to be consulted. There appeared to be a strong feeling of trust towards traditional healers and respondents reported taking their advice seriously. A common theme was that these individuals shared the same cultural values and were able to communicate more freely with them than allopathic health-care providers. In particular, respondents from lower castes and with low literacy stated that these practitioners were their first port of call when their children were ill. In general, the community appeared to rely heavily on such religious healers, often going back and forth between them and local 'private doctors'. Baghats are Hindu priests (from any caste) who specialise in tackling black magic and sorcery, including purging evil spirits. Hindu respondents explained that they chanted and prayed for their sick children. The Muslim molvis did the same thing for their community. For instance, caregivers often reported that they asked priests to provide amulets to protect their children from the 'evil eye'. According to the majority of the respondents, the advantage of these healers was their low cost compared with 'private doctors' or primary health centres.

*AYUSH doctors hold degrees in non-allopathic medicine (AYUSH represents practitioners of Ayurveda, Yoga and Naturopathy, Unani, Siddha and Homoeopathy). In Bihar, the majority of doctors stationed in rural health centres outside the primary health centres are AYUSH. These health-care providers act as general practitioners and may refer patients to primary health centres or hospitals in case of emergencies. 


\section{Factors that influence bealth-seeking behaviour with regard to the community management of acute malnutrition programme}

Several factors significantly affected the health-seeking behaviour of the community in Biraul with regard to their utilisation of the CMAM programme. These factors can be categorised as: (i) social and cultural (perception of the problem by the patient and others around her/him); (ii) logistical (existing transport, availability and proximity of medical care); and (iii) economic (transport costs, wage loss, affordability of health care and acceptance of costs). Other important factors included the previous experiences of the caregivers and their perception and understanding of how prescribed medicines work on the body.

\section{Social and cultural factors}

All respondents perceived undernutrition as the child being 'too weak'. Thus, while families acknowledged that the child was not entirely healthy, they did not necessarily see it as a disease that needed to be treated. As in many other resource-poor settings, caregivers reported that relatives and neighbours influenced or even determined treatment decisions, especially in serious illness and/or life-threatening circumstances. The majority of women interviewed appeared to lack decision-making autonomy and reported that it was necessary for them to ask their mothers-in-law or other senior, female family members for advice on what to do with a sick child. Figures of lay authority, such as village elders, appeared to play a major role in the diagnosis and treatment of illness. Mothers noted that these individuals sometimes even decided on the diagnosis before consulting a traditional medical practitioner or health-care worker.

An additional factor mentioned by the majority of respondents influencing health-seeking behaviour was temporary migration. They explained that roughly twice per year women took their children to their home villages to stay for a month at a time. During these periods they were unable to attend their local health centres, leading to difficulty in completing longer treatments such as CMAM. Finally, the cultural practice of mothers remaining strictly within the house following the birth of a child was widely mentioned as a reason for difficulty in attending the CMAM programme if another child was enrolled.

\section{Logistical factors}

The availability of medical care played an important role in the caregivers' decision-making process. Modern healthcare facilities, such as the block-level primary health centres, were considered to be located only in more populous areas and respondents emphasized that no appropriate health facility was available at the village level. Caregivers living further away from CMAM facilities reported that it was difficult for them to reach the therapeutic feeding centres, especially during heavy rains when transport is challenging due to frequent flooding.
In contrast, every village was reported to have a traditional health practitioner and/or a Muslim or Hindu priest. Even if most of the respondents did not necessarily consider these health-care providers to be ideal, they felt that they were sometimes their only option.

Many respondents spoke about the difficulties of travelling long distances to CMAM facilities as a major barrier for them to access health care. Mothers stressed the fact that in addition to caring for their sick child, they had to take care of housework, work in the fields (especially around planting or harvest times) and look after their other children. For caregivers commuting from outside the block in particular, visits often took an entire day since travelling could entail a $4 \mathrm{~h}$ round trip in addition to the $2-3 \mathrm{~h}$ waiting time at the therapeutic feeding centre. Hence other family members had to shoulder an extra burden of work and thus would not always encourage mothers to visit the CMAM programme.

\section{Economic factors}

The choice of whether to access care was linked more to the perception of the disease and hence the importance of how much money and time should be spent on the treatment, and within which sector. Most of the caregivers complained that they could not afford the transport costs to come each week for the treatment in the CMAM programme, which appeared to be an important influence on the decision to attend or complete treatment.

\section{Other factors}

Based on the responses of mothers whose children had been treated within the programme, the overall perception of CMAM was positive. Weight gain was seen as a measure of success and the positive perception of the service was expressed by mothers, family members and community participants who were aware of the programme. However, a significant number of caregivers said that they did not consider the peanut oil-based treatment offered to their children as effective enough and consequently would frequently think about stopping the treatment. The caregivers wanted to see immediate results when their child started any treatment, so many were discouraged when the child did not rapidly gain weight.

\section{Discussion}

Traditional beliefs inform much of the understanding of undernutrition in the communities in Biraul. As found in analyses in other local contexts, undernutrition is seen not as a disease in itself but as a consequence of different disease conditions ${ }^{(23-25)}$. Often spirits or witchcraft are thought to be involved $^{(26)}$. For example, in Sierra Leone and Liberia, undernutrition and associated weight loss is metaphorically seen as the result of a witch sucking the child's blood and eating its flesh ${ }^{(27)}$. Similarly, undernutrition is also occasionally seen as the result of witchcraft in Biraul. In the 
context of their research on practices of Maithili women in India, Reissland and Burghart (1988) pointed out that mothers spit on their breasts before nursing their child as a precautionary measure against the influence of witchcraft $^{(28)}$.

In general, our findings did not differ between households with or without malnourished children, and our results did not suggest that health-seeking behaviour was age specific. However, our study would have been strengthened by more focus on age-specific differences between children and the associated caregiver attitudes and behaviour. During our research it became obvious that respondents had clear ideas about what made a child healthy and strong, what constitutes the appropriate size of their babies and what food they should be given. This is consistent with other research, where according to the mothers a baby has the appropriate size when it is 'strong', rather than large and 'puffy'(22). Also confirming research by Reissland and Burghart (1987) ${ }^{(29)}$ and Winch et al. $(2005)^{(26)}$, the concept of strength and weakness was linked to good care of the child by means of giving regular massages.

In the current study, a child was considered to be healthy when it is not crying, when it plays and when it is free of diseases such as fever, diarrhoea or vomiting. Prolonged illhealth leading to loss of weight is interpreted with different traditional disease concepts, such as mamarcha, jallachatu, chamaki and hakarani, corresponding to different severities of undernutrition. These disease concepts have crucial implications for how undernutrition is managed, i.e. how much importance mothers and other family members give undernutrition and how they treat it. Similar findings have been discovered in other resource-poor settings ${ }^{(29-33)}$. These traditional disease concepts influence how undernutrition is viewed, with healers and priests of the folk sector being considered as important as health-care professionals ${ }^{(27,30,33)}$.

From our results, it appears common for families to favour boys over girls, especially when resources are limited. Age and gender may determine the pathway for cure, with greater care given to male children. This may explain in part why existing Indian nutritional programmes admit more girls than boys for treatment of undernutrition $^{(34)}$, although idiosyncratically mothers of female children may not seek treatment for undernutrition as often as those of male children.

Community experiences, such as the failure or success of treatments within the popular or folk sector ${ }^{(35)}$ and the perception of how medication works on the body, can also influence health-seeking behaviour. Nichter (1996) demonstrated the prevalent idea that a medicine, which works for one person, might not be effective for another because of a difference in body constitution ${ }^{(21)}$. This is reflected in caregivers' description of a child's capacity to 'take to' the medicine.

The popular health-care sector where ill-health is first recognised and health-care activities are initiated is based within the family. It is the most important part of a community's medical system and according to Kleinman (1981) heavily underestimated ${ }^{(35)}$. After people have consulted with the 'folk and professional sector, they go back to the popular sector to evaluate and decide what to do next ${ }^{\text {(36) }}$. In the present study we found one of the main causes of delay in mothers accessing the CMAM facilities was their desire to initially consult traditional health practitioners. The use of traditional healers in allopathic health streams has been widely documented ${ }^{(37-41)}$, especially in areas where there is a dearth of allopathic health services. As such, there appears to be an opportunity to provide these practitioners with a role in educating the community, identifying children at risk of undernutrition and making referrals to the CMAM programme. Additionally caregivers chose to first discuss the appropriate course of action with other family members, suggesting a relative lack of decision-making power, which are findings consistent with those reported in other resource-poor settings ${ }^{(26,42-45)}$.

Nearly a quarter of mothers did not perceive CMAM treatment as being sufficiently adequate or quick acting and some preferred to stop the treatment or return back to the popular/folk sector. Similarly, in a study on patient adherence on tuberculosis treatment, Munro et al. (2007) observed that not experiencing an improvement led to the abandonment of treatment at an early stage ${ }^{(46)}$. This characteristic was influenced by the patients' idea of how medicine works on the body. As mentioned earlier from Nichter's South Indian case study ${ }^{(21)}$ : '[...] in order for the body to "take to" a new food or type of medicine, it must first adjust to its properties.'

Therefore, the access to health care cannot be taken for granted. The perception of the problem, proximity of medical care ${ }^{(47)}$, perception of effectiveness of medication, financial aspects as well as the dependence on decision-making power of mothers-in-law ${ }^{(45)}$ are decisive in determining health-seeking behaviour and care for a malnourished child. These understandings must be taken into account both in health promotion and in programme delivery. For this reason, any programme tackling undernutrition must first understand the beneficiaries' perception of the problem.

\section{Addressing the understandings and beliefs of undernutrition}

The need for local understandings, beliefs and motivations to be incorporated into any health programme so dependent on community buy-in is well established. However, it is clear that in the current programme this aspect of the approach was lacking, with the result that important contacts in the community were not being involved that may have a substantial impact on uptake and attrition in the CMAM programme.

In order to approach the problem and adapt perceptions of undernutrition, a health promotion strategy for 
raising community awareness is crucial. We provide a number of suggestions to target undernutrition and the beliefs surrounding undernutrition that should be incorporated into CMAM programming.

Primary interventions should focus on the dissemination of basic information about undernutrition and on clarification of misconceptions. The aim should be to raise understanding and awareness of severe malnutrition as a disease, while empowering mothers to decide whether they want to seek treatment for their child or not. Longer term, secondary interventions should address behaviour change, taking into account the socio-economic, religious, cultural and political consequences of changes in the perception of undernutrition and the adaptation of healthseeking behaviour of caregivers. Above all, active engagement and collaboration with communities is essential in order to address the barriers to enable change in such societies. The goal for health promotion should be the development of strategies and methods that enable individuals, families, groups, organisations and communities to play active roles in protecting and sustaining their own health ${ }^{(48)}$. The process should empower communities to make decisions, modify behaviours and change social conditions.

The success or failure of health programmes ultimately rests on how well they adapt to the local population. A fundamental focus of the training of health personnel should be the importance of being responsive and respectful to the traditions, religion and customs in the environment they are or will work in ${ }^{(48-51)}$.

Language is also important in the delivery of messages to the community. In countries with many dialects, it is important that local language skills are considered in communication strategies. For example, the staff within the CMAM programme routinely used the Hindi word kuposan to explain undernutrition. Yet, many of the respondents did not understand this, as it is an elite Hindi word that is rarely used in these communities. Hindi is widely spoken in northern India; however, the standard of Hindi used may sometimes not be appropriate for the local context.

In addition to using local language, disease can be understood through the use of local concepts. Expressions such as mamarcha and jallachatu can be used by health workers in the Biraul area to explain undernutrition to communities who would normally not think in terms of allopathic medicine. Communities need to be made aware of undernutrition: what it is, how it is caused, how it appears, how it manifests itself in the body and how it can be treated. However, before delivering this information, health educators need to incorporate communities' perception of undernutrition in order to create coherent messages. Also, the concept of strength and weakness has to be taken into consideration when talking about a healthy child. For example, CMAM care providers may put too much emphasis on baby size rather than baby strength when talking about a healthy child.

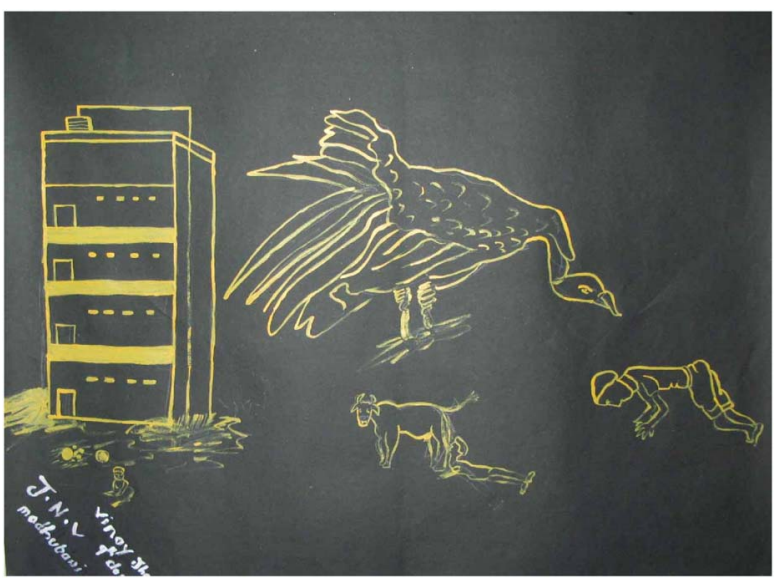

Fig. 1 (colour online) Image of jallachatu. Jallachatu is believed to occur when a vulture flies over the pregnant mother during pregnancy. Drawing from an exhibition on malnutrition in Bihar by artist Vinoy Jha (permission to use granted as per creative commons licence)

MSF held an art exhibition in Darbhanga district with the tagline 'I am not hungry, I am sick', with the aim of identifying mamarcha and jallachatu as diseases that needed medical treatment. One painting depicted the vulture that is thought to bring the weakness associated with undernutrition to the child (jallachatu). This painting was used subsequently by CMAM health educators to explain to mothers that the condition was undernutrition and that it could be effectively treated within the CMAM programme (Fig. 1). Awareness-raising and information campaigns in the community have since taken the form of theatrical plays that travel from village to village or folk songs in the local language, which build upon these local idioms to communicate undernutrition to the community in a more comprehensible and accessible format.

Caregivers often do not make decisions alone; frequently, family elders decide whether a mother may seek and receive treatment for her child. Therefore, it seems imperative that information, education and communication programmes target communities broadly, including educators, youth and decision-making groups, and in particular those whose opinions are respected and considered most important in the social structure. Crucially, community engagement programmes must include both priests and healers, who could assist in encouraging appropriate referrals into the CMAM programme.

\section{Acknowledgements}

Acknowledgements: The authors thank Stephanie Bartlett, Grigor Simonyan, Silvia de Weerdt and Anita Sackl for useful comments on drafts, and Priya Shetty, Sarah Venis and Sandra Bauer for editing assistance. Financial support: Funding was done as part of normal MSF operational programming. This means that the assessment was 
funded by money provided for routine operations (in this case the nutrition programme) by a mixture of private and individual donations as per usual MSF fundraising. The funders had no role in study design, data collection and analysis, decision to publish or preparation of the manuscript. Conflict of interest: None. Authorship: D.B. designed the study and conducted all interviews. S.B. was responsible for developing the CMAM programme. Both authors contributed to writing the manuscript. Ethics of buman subject participation: This report meets the MSF Ethics Review Board criteria (http://fieldresearch.msf.org/msf/handle/ $10144 / 294968$ ) for analysis of routinely collected programme data. The MSF CMAM programme is conducted in collaboration with the Bihar State Health Society, the usual operating procedure for non-governmental organisations working within the health sector in Bihar State. Informed verbal consent was sought at the beginning of every conversation. Prior to any interview or discussion the interview team explained the purpose of the study to the participants; no information was collected without prior consent. The verbal consent was documented in the notes transcribed and was witnessed by the translator. The respondents were assured that all data would be handled confidentially, that participation or non-participation in the study would not have any influence on the treatment they received for their children and that they had the right to withdraw at any time during the discussion. The respondents were made aware that the purpose of the study was to improve the quality of service that the CMAM programme provided to the community and that recommendations based on their anonymised inputs would be made to the health-care providers.

\section{Supplementary material}

To view supplementary material for this article, please visit http://dx.doi.org/10.1017/S1368980015000440

\section{References}

1. International Institute for Population Sciences \& Macro International (2007) National Family Health Survey (NFHS-3), 2005-06, India: Key Findings. Mumbai: IIPS; available at http://www.measuredhs.com/pubs/pdf/sr128/ sr128.pdf

2. Chalasani S (2012) Understanding wealth-based inequalities in child health in India: a decomposition approach. Soc Sci Med 75, 2160-2169.

3. Pelletier DL, Frongillo EA Jr, Schroeder DG et al. (1995) The effects of malnutrition on child mortality in developing countries. Bull World Health Organ 73, 443-448.

4. Gaur K, Keshri K \& Joe W (2013) Does living in slums or non-slums influence women's nutritional status? Evidence from Indian mega-cities. Soc Sci Med 77, 137-146.

5. Kumar S (2006) Malnutrition in children of the backward states of India and the ICDS programme. $J$ Health Dev available at http://www.vri-online.org.uk/ijrs/april2006/ malnutrition.pdf (accessed February 2012).
6. Pathak PK \& Singh A (2011) Trends in malnutrition among children in India: growing inequalities across different economic groups. Soc Sci Med 73, 576-585.

7. Website of the Dharbanga Bihar District Administration, Health Department (2014) http://darbhanga.bih.nic.in/dar_ health.htm (accessed November 2014).

8. Press Information Bureau, Government of India (2012) Per capita income. http://pib.nic.in/newsite/erelease.aspx? relid=81913 (accessed November 2012).

9. Ministry of Health and Family Welfare, Government of India (2012) Bihar state report. http://Mohfw.nic.In/Nrhm/State\% 20files/Bihar.htm (accessed November 2013).

10. Espie E, Pujol CR, Masferrer M et al. (2011) Acute malnutrition and under-5 mortality, northeastern part of India. J Trop Pediatr 57, 389-391.

11. Ministry of Home Affairs, Government of India (2011) Census of India 2011. http://www.censusindia.gov.in/2011prov-results/PPT_2.html (accessed June 2013).

12. Ministry of Health and Family Welfare (2011) Operational Guidelines on Facility-Based Management of Children with Severe Acute Malnutrition. New Delhi, India: Government of India.

13. United Nations (1986) How to Weigh and Measure Children - Assessing the Nutritional Status of Young Children in Housebold Surveys. New York: UN Department of Technical Co-operation for Development and Statistical Office; available at http://unstats.un.org/unsd/publication/unint/dp_ un_int_81_041_6E.pdf

14. Wilford R, Golden K \& Walker DG (2012) Cost-effectiveness of community-based management of acute malnutrition in Malawi. Health Policy Plan 27, 127-137.

15. Burza S, Mahajan R \& Marino E (2012) The use of SQUEAC methodology to assess CMAM for severe acute malnutrition (SAM) programme coverage in Bihar, India. Poster presented at MSF Scientific Day 2012, London, 25 May 2012.

16. Burza S, Mahajan R, Marino E et al. (2015) Communitybased management of severe acute malnutrition in India: new evidence from Bihar. Am J Clin Nutr 101, 1-13.

17. Taneja G, Dixit S, Khatri A et al. (2012) A study to evaluate the effect of nutritional intervention measures on admitted children in selected nutrition rehabilitation centers of Indore and Ujjain divisions of the state of Madhya Pradesh (India). Indian J Community Med 37, 107-115.

18. Singh K, Badgaiyan N, Ranjan A et al. (2013) Management of children with severe acute malnutrition in India: experience of nutrition rehabilitation centres in Uttar Pradesh, India. Indian Pediatr 51, 21-25.

19. Khan ME \& Manderson L (1992) Focus groups in tropical diseases research. Health Policy Plan 7, 56-66.

20. Patton Q (editor) 2002) Qualitative Research \& Evaluation Methods. Thousand Oaks, CA: SAGE Publications.

21. Nichter M (1996) Popular perceptions of medicine: a South Indian case study. In Anthropology and International Health. Asian Case Studies, pp. 203-237 [M Nichter and M Nichter, editors]. Amsterdam: Gordon \& Breach.

22. Nichter M \& Nichter M (1996) The ethnophysiology and fold dietetics of pregnancy: a case study from South India. In Anthropology and International Health. Asian Case Studies, pp. 35-71 [M Nichter and M Nichter, editors]. Amsterdam: Gordon \& Breach.

23. Helman CG (2000) Culture Health and Illness, 4th ed. London: Hodder Arnold.

24. Burtscher D (2004) Searching for health care after 10 years of war. The Mende and Kissi in the Kailahun district, Sierra Leone. Vien Ethnomed Newsl 7, 3-14.

25. Burtscher D (2002) Geidj Faye: 'No and no rimeem' - 'Ich bin im wissen geboren'. Leben und Arbeit eines traditionellen Teilers der Seereer-Siin, Senegal (I was born with knowledge: Life and work of a traditional healer of the Seereer-Siin, Senegal). Wiener ethnomedizinische Reihe bd. 2. Berlin: VWB. 
26. Winch PJ, Alam MA, Akther A et al. (2005) Local understandings of vulnerability and protection during the neonatal period in Sylhet district, Bangladesh: a qualitative study. Lancet 366, 478-485.

27. Gittins AJ (1987) Mende Religion. Aspects of Belief and Thought in Sierra Leone. Studia Instituti Anthropos no. 41. Nettetal: Steyler Verlag - Wort und Werk.

28. Reissland N \& Burghart R (1988) The quality of a mother's milk and the health of her child: beliefs and practices of the women of Mithila. Soc Sci Med 27, 461-469.

29. Reissland N \& Burghart R (1987) The role of massage in South Asia: child health and development. Soc Sci Med 25, 231-239.

30. Cleland JG \& Van Ginneken JK (1988) Maternal education and child survival in developing countries: the search for pathways of influence. Soc Sci Med 27, 1357-1368.

31. Rodrigues M, Patel V, Jaswal S et al. (2003) Listening to mothers: qualitative studies on motherhood and depression from Goa, India. Soc Sci Med 57, 1797-1806.

32. De Zoysa I, Bhandari N, Akhtari N et al. (1998) Careseeking for illness in young infants in an urban slum in India. Soc Sci Med 47, 2101-2111.

33. Jain M, Nandan D \& Misra SK (2006) Qualitative assessment of health-seeking behaviour and perceptions regarding quality of health care services among rural community of district Agra. Indian J Community Med 31, 140-144.

34. Burza S, Mahajan R \& Salse N (2013) Mid upper arm circumference (MUAC) $\geq 120 \mathrm{~mm}$ as a simple, safe and effective discharge criterion. Poster presented at MSF Scientific Day 2013, London, 10 May 2013.

35. Kleinman A (1981) Patients and Healers in the Context of Culture: An Exploration of the Borderland between Anthropology, Medicine and Psychiatry. Berkeley, CA: University of California Press.

36. Pool R \& Geissler W (2005) Medical Anthropology. Understanding Public Health. Maidenhead: Open University Press.

37. Poudel KC, Jimba M, Joshi AB et al. (2005) Retention and effectiveness of HIV/AIDS training of traditional healers in far western Nepal. Trop Med Int Health 10, 640-646.

38. Furin J (2011) The role of traditional healers in communitybased HIV care in rural Lesotho. J Community Health $\mathbf{3 6}$, 849-856.
39. Colvin M, Gumede L, Grimwade K et al. (2003) Contribution of traditional healers to a rural tuberculosis control programme in Hlabisa, South Africa. Int J Tuberc Lung Dis 7 , 9 Suppl. 1, S86-S91.

40. Poudyal AK, Jimba M, Murakami I et al. (2003) A traditional healers' training model in rural Nepal: strengthening their roles in community health. Trop Med Int Health 8 , 956-960.

41. World Health Organization (2002) WHO traditional medicine strategy 2002-2005. http://whqlibdoc.who.int/hq/2002/ WHO_EDM_TRM_2002.1.pdf (accessed January 2014).

42. Good CM (1987) Ethnomedical Systems in Africa: Patterns of Traditional Medicine in Rural and Urban Kenya. New York: Guilford Press.

43. Hausmann-Muela S, Ribera JM \& Nyamongo I (2003) Health-seeking Behaviour and the Health System Response. DCPP Working Paper no. 14. London: London School of Health and Tropical Medicine.

44. Janzen JM (1978) The Quest for Therapy: Medical Pluralism in Lower Zaire. Berkeley, CA: University of California Press.

45. Griffiths P, Matthews Z \& Hinde A (2002) Gender, family, and the nutritional status of children in three culturally contrasting states of India. Soc Sci Med 55, 775-790.

46. Munro AS, Lewin SA, Smith HJ et al. (2007) Patient adherence to tuberculosis treatment: a systematic review of qualitative research. PLoS Med 4, 1230-1245.

47. Mistry R, Galal O \& Lu M (2009) Women's autonomy and pregnancy care in rural India: a contextual analysis. Soc Sci Med 69, 926-933.

48. Kiefer CW (2007) Doing Health Anthropology: Research Methods for Community Assessment and Change. New York: Springer Publishing Company.

49. Van Der Geest S \& Reis R (2002) Ethnocentrism: Reflections on Medical Anthropology. Amsterdam: Aksant Academic Publishers.

50. Winkelman M (2009) Culture and Health. Applying Medical Anthropology. San Francisco, CA: Jossey-Bass.

51. Jaffré Y \& Olivier De Sardan JP (2003) Une médecine inhospitalière. les difficiles relations entre soignants et soignés dans cinq capitales c'Afrique de l'ouest. Paris: Karthala. 